\section{An audit of implant practice websites: content and regulatory compliance}

\author{
H. Raimundo ${ }^{1}$ and P. K. Robinson ${ }^{* 2}$
}

VERIFIABLE CPD PAPER
IN BRIEF
- Presents information regarding the content of implant practice websites with respect to their compliance with current legal and professional standards.
- Explores the common issues resulting in failure in meeting current regulatory standards, and describes trends over the past decade.
- Encourages registrants and practice owners to review the content of their websites on a regular basis.

\begin{abstract}
Aims and objectives To audit the content of dental practice websites offering dental implant services against a framework based on the GDC 2012 Guidelines for Ethical Advertising and other relevant advertising standards. Methods An audit framework was constructed and applied to the top fifty websites resulting from a Google UK search using the search term 'dental implant specialist'. Results Compliance with many elements of the GDC Guidance remains poor. Sixty-eight percent of websites claimed that the practitioner providing the service was a GDC registered specialist, though examples were found where this claim was unfounded. Fourteen percent of practice websites claimed that the service was being carried out by an 'implant specialist' and $16 \%$ claimed the practitioner was an 'implantologist'; the majority of sites using these terms (10\%) involved practitioners that had no specialist status. The display of potentially misleading memberships and fellowships of a range of dental associations, academies, societies and foundations remains common (52\%), as does the adoption of the title 'Dr' (60\%). Conclusion Comparison with earlier studies indicates that compliance with recent GDC standards is generally improving, though whether the pace of improvement is seen as acceptable or not is something that policymakers and regulatory authorities may need to consider further.
\end{abstract}

\section{INTRODUCTION}

The dental practice website is now seen as a key part in the success of a modern dental practice, ${ }^{1-4}$ and there is strong anecdotal and research evidence to suggest that patients use the Internet extensively to research their presenting dental/oral conditions and identify potential providers of dental treatment. ${ }^{5}$ Internet usage in the UK has risen massively over recent years, such that in 2012, 33 million adults in Great Britain use the Internet almost every day. This represents $68 \%$ of those aged 16 and over, and is more than double that found in $2006 .{ }^{6}$ Use of the Internet for finding information about goods and services is second in popularity among UK adults, only marginally behind the use of the Internet to send or receive email. ${ }^{6}$

Within the UK, dental professionals are required to advertise in accordance with the standards set out in the UK Advertising Codes produced by the Committees of Advertising Practice (CAP), and administered

\footnotetext{
Jersey Smile Centre, 3 Bath Street, St. Helier, Jersey, JE2 4ST; ${ }^{2}$ School of Psychology, University of Central Lancashire, Preston, PR1 2HE

Correspondence to Dr Peter K Robinson

Email:pkrobinson@uclan.ac.uk
}

\section{Refereed Paper}

Accepted 21 October 2014

DOI: 10.1038/sj.bdj.2014.1101

${ }^{\circledR}$ British Dental Journal 2014; 217: 673-677 by the Advertising Standards Authority (ASA). As such, all materials must be legal, decent, honest and truthful. ${ }^{7}$ The ASA has the legal power to remove any advertising material that they judge to be unsuitable, and can also refer persistent offenders to the Office of Fair Trading for legal action. The ASA Code has a specific section describing standards that relate to medicines, medical devices, health-related products and beauty products. $^{7}$ The ASA does not, however, regulate all issues related to advertising and one notable exception is that advice on discrimination and equality law falls under the terms of the Equality and Human Rights Commission. The Equality Act came into force in October 2010, replacing the earlier Disability Discrimination Act (DDA). It is noteworthy that this Act is 'anticipatory', meaning that service providers cannot wait until a disabled person wants to use their service before making adjustments. Rather they must anticipate in advance (and on an ongoing basis) what disabled people with a range of impairments (sight, hearing, mobility and cognitive impairments) might reasonably need. Under the Act, it may be unlawful for a website to have links that are not accessible to a screen reader, have core information and forms in a pdf-only format that cannot be read by a screen reader, or use text, colour contrasting and formatting that make the website inaccessible to a partially sighted user. As yet, there have been no cases brought to UK courts under the Act, meaning that there is no case law guidance. However, the Royal National Institute of Blind People (RNIB) has in the past challenged two high profile brands over their website accessibility, with the cases being settled out of court, maintaining the anonymity of the organisations involved. More recently, in 2012, the RNIB served legal proceedings against Bmibaby Ltd. over their 'failing to ensure web access for blind and partially sighted customers' arguing that blind people visiting the website were unable to book flights since the website was not accessible to screen readers and required the use of a mouse (blind people are unable to use a computer mouse because they cannot see the accompanying on-screen pointer). These and future cases will no doubt provide further clarity as to the standards now required of business websites under the Equality Act.

General guidance has also been available to dental professionals for some time within the GDC's Standards for Dental Professionals, written in $2005 .{ }^{8}$ With respect to advertising and patient interactions, this states that dental professionals should:

- Not make any claims which could mislead patients

- Communicate effectively with patients, 
explaining options (including risks and benefits) and giving full information on proposed treatment and possible costs

- Find out about, and follow, any laws and regulations which affect their work, premises, equipment and business

- Justify the trust that patients, the public and colleagues have in them by always acting honestly and fairly.

In 2012 the GDC issued further guidance, relating specifically to the advertising standards required of dental professionals. ${ }^{9,10}$ The guidelines specified that the professional qualification, the country from which that qualification was derived and the GDC registration number must be provided for all dental professionals providing dental care mentioned on a website. In addition dental practice websites must display the name and geographic address at which the dental service is established; the contact details of the dental service, including email address and telephone number; the GDC's address and other contact details, or a link to the GDC website; details of the practice's complaints procedure and information of who patients may contact if they are not satisfied with the response (namely the relevant NHS body for NHS treatment and the Dental Complaints Service for private treatment); and the date the website was last updated.

The GDC also require websites to be maintained with up-to-date information, but stated that websites must not display information comparing the skills or qualifications of any dental professional providing any service with the skills and qualifications of other dental professionals. ${ }^{9}$

Advice on the use of the term Specialist and on the avoidance of the use of honorary degrees and memberships, or fellowships, professional associations or societies was also given. ${ }^{9}$

In March 2012 the DDU, welcomed the clarifications that the GDC had produced, and urged dental professionals to be extremely careful about the information that they display on their promotional material, such as signs to leaflets; and suggested that even choosing an appropriate name could see dental professionals in breach of the guidance and ASA regulations. ${ }^{11}$

Implant dentistry is perhaps one of the most competitive areas of primary care dentistry at this time. Since it is not generally available under the NHS, patients who wish to consider dental implants as a treatment option are likely guided by personal and professional recommendations, but are also likely to compare and select options using the information provided by dental professionals on the Internet. ${ }^{5}$ While

\section{Table 1 Website audit framework}

Question/criterion
1. Does website make it clear whether the practice is NHS, mixed or wholly private?
$\begin{aligned} & \text { 2. Does website display professional qualification of practitioner and the country from } \\ & \text { which that qualification is derived? }\end{aligned}$

Positive response (\%) which that qualification is derived?

3. Does website display GDC registration number of practitioner? 42 4. Does website display name and geographic address of practice?

5. Does website display contact details, including e-mail address and telephone number of practice?

6. Does website display GDC address and other contact details, or a link to the GDC website? 38

7. Does website display details of the practice's complaints procedure and information of who patients may contact if they are not satisfied with the response (NHS body / Dental Complaints Service)?

\begin{tabular}{|l|l}
\hline 8. Does website display date the website was last updated? & 46
\end{tabular}

9. Does website display any information comparing the skills or qualifications of any dental professional providing any service with the skills and qualifications of other dental professionals?

\begin{tabular}{|l|l}
\hline 10. Does website display information regarding practitioner on a GDC specialist list? & 58
\end{tabular}

\begin{tabular}{|l|l|l}
\hline 11. Is anyone not on a specialist list describing themselves as a specialist or 'specialist in...'? & 8
\end{tabular}

\begin{tabular}{|l|l}
\hline 12. Does the website use the word specialist in the URL (domain name)? & 10
\end{tabular}

13. Is anyone not on a specialist list using a title that may imply specialist status such as orthodontist, periodontist, endodontist, etc.?

14. Is there any claim that the practitioner is an implant specialist (if so what skills and qualifications)?

15. Is there any claim that the practitioner is an implantologist (if so what skills and qualifications)?

\begin{tabular}{|c|c|}
\hline 16. Are there any other potentially confusing titles or descriptions used? & 34 \\
\hline $\begin{array}{l}\text { 17. Are honorary degrees and/or memberships or fellowships of professional associations or } \\
\text { societies being presented? }\end{array}$ & 52 \\
\hline 18. Do dentists use the title 'Dr'? If so, was that title obtained abroad? & 60 \\
\hline 19. Do dentists use other titles (e.g. Prof.)? If so, was that title obtained abroad? & 6 \\
\hline 20. Is the practice on the BDA Good Practice Scheme? & 16 \\
\hline $\begin{array}{l}\text { 21. Is there any mention about the website being in accordance with rules of the } \\
\text { Advertising Standards Authority? }\end{array}$ & 0 \\
\hline 22. Is there any mention about the website accordance with rules of the Office for Fair Trading? & 0 \\
\hline 23. Is there any claim or statement that could lead the patients to unfulfilled expectations? & 4 \\
\hline 24. Is the website accessible and easy to navigate? Text resizing & 0 \\
\hline $\begin{array}{l}\text { 25. Is the website accessible and easy to navigate, meeting WCAG } 1.0 \text { level-A; WCAG } 2.0 \\
\text { level-A; or WCAG } 2.0 \text { double-A standards }\end{array}$ & $20 ; 8 ; 6$ \\
\hline $\begin{array}{l}\text { 26. Is reference to the fact that the dentist adheres to the rules governing the profession? } \\
\text { (GDC Standards for Dental Professionals). }\end{array}$ & 8 \\
\hline 27. Are there any case presentations? & 56 \\
\hline 28. And are they attributed to one of the dentists at the practice? & 18 \\
\hline 29. Is there any information about the fees? & 64 \\
\hline 30. If yes, is the price for a fully restored single implant provided? & 46 \\
\hline
\end{tabular}

precise figures are difficult to establish, the implant system supplier Straumann reported that in 2011 there were over 100,000 dental implants being placed annually within the UK. ${ }^{12}$ Additionally, a significant number of UK patients travel abroad to have implant treatment, likely being influenced by the lower costs of treatment overseas. ${ }^{13}$

Aware that the educational and clinical experience of those offering implants to the public varies considerably, the GDC issued a policy statement in 2012, stating 
that UK-qualified dentists would not be expected to be competent to practise implant dentistry without undertaking structured postgraduate training and assessment of competence. ${ }^{14}$ This suggests that education providers, and dentists who wish to practise implant dentistry, should refer to the Training Standards in Implant Dentistry, published by the Faculty of General Dental Practice (UK), as the authoritative source of training standards for implant dentistry for dentists in the UK. ${ }^{14}$

A year after the clarification of advertising standards by the GDC, and in the light of increased publicity regarding the potential risks of implant treatment, ${ }^{15}$ this study aims to review the current state of dental practice websites, with especial emphasis on those providing implant services.

\section{METHODS}

In the UK, nine out of ten Internet searches use the Google Search engine. ${ }^{16}$ Consequently, a search methodology was designed to mimic how a member of the UK public might use Google to identify clinical providers of dental implant services. Using the Google Advanced Search facility (https://www.google.co.uk/advanced_search) the search term 'dental implant specialist' was entered into the 'Find pages with all these words' selection field. The search was further restricted by setting the search region to the UK.

The search enabled the identification of the first 50 dental practice websites advertising implant services. These 50 sites were subsequently reviewed using the audit framework shown in Table 1. A recent study demonstrated that the ten websites listed on the first Google results page actually generate $92 \%$ of all traffic from an average Google search, and that the 50 websites on the first five pages generate $98.9 \%$ of all traffic. ${ }^{17}$ The methodology used in this study would therefore represent with good certainty the websites that would likely be considered by members of the UK public using the Internet to search for a dental implant specialist.

Regarding website accessibility issues, in 2005 the RNIB recommended that all websites exceed the basic level of compliance (Level A) that the World Wide Web Consortium (W3C) recommend in version 1.0 of their Website Content Accessibility Guidelines (WCAG), and aim for Double-A compliance. In 2008 the W3C introduced version 2.0 of the guidelines. It is the W3C's current recommendation that any new and updated content on websites comply with their WCAG 2.0 guidelines. Compliance against these standards was therefore checked with the AChecker online evaluation tool (http://achecker.ca/checker/ index.php) and the number of known problems recorded. As there are often accessibility issues with website homepages, this test was done on the page that contained the most information about the registrant (often the 'about us' or the 'meet the team' page)

\section{RESULTS AND DISCUSSION}

It is clear from Table 1 that various aspects of the GDCs guidance ${ }^{9}$ are being adhered to more completely than others. In virtually all cases dental practice websites clearly described the name, address and contact details of the website ( $94 \%$ positive response) together with the professional qualifications of the practitioner (84\%), though the latter was not always accompanied by the institution or country from which such qualifications were gained.

Surprisingly only $64 \%$ websites made the GDC number of registrants available to the public, and less (34\%) had a logo or link to the GDC as the regulatory authority. Only $8 \%$ websites made reference to the fact that the registrant adheres to the GDC Standards for Dental Professionals. Similarly few websites (26\%) made available a complaints policy or procedure for use by patients if dissatisfied.

In many cases dental websites still contain inadequate information to enable potential patients to make fully informed choices. Only 64\% of websites had any information about the cost of the services being offered, and even fewer (46\%) provided sufficient detail to allow comparison of the price of any common implant procedure. The information that is available suggests that currently the average charge for a fully restored single implant is $£ 2270$, with individual figures ranging from $£ 1200-3,700$ for the procedure.

With respect to qualifications and experience, while the GDC currently recognise 13 specialist lists, this does not include the specialism of 'implantology'. Even so, this study reveals that $14 \%$ of practice websites claimed that an 'implant specialist' was carrying out the surgery, and 16\% of websites claimed that the practitioner was an 'implantologist' (potentially implying specialist status). The GDC clearly state that only dentists who are on a GDC specialist list may use the title 'Specialist' or describe themselves as a 'specialist in..... Those not on a specialist list must avoid using terms that may imply specialist status, such as orthodontist, periodontist or endodontist. ${ }^{9}$ Furthermore, while the area of implantology is not specifically mentioned in current GDC guidance, ${ }^{9}$ this does clearly state that since there are no specialist lists for dental care professionals (DCPs) such registrants must ensure that they do not mislead patients by using titles that could imply specialist status, such as 'smile specialist' or 'denture specialist'. An extension of this argument (and hence these restrictions) to GDPs claiming to be 'implant specialists' or 'implantologists', would therefore seem entirely logical and reasonable. It is worth noting that the majority of sites that used these terms (10\%) actually involved practitioners that were not on any of the GDC's specialist lists. These findings suggest that there is significant potential to mislead the public when practitioners use such terms, which have little real meaning in terms of actual register status, experience or proven clinical ability.

Of the practice websites reviewed, 58\% claimed that at least one practitioner did have specialist status, with many websites listing staff on a number of specialist lists, as follows: periodontics $36 \%$, prosthodontics $32 \%$, oral surgery $26 \%$, orthodontics $22 \%$, endodontics $18 \%$ and restorative dentistry $14 \%$. However, it likely remains difficult for the general public to know whether any of these established dental specialisms equip the practitioner to place implants, or indicates their competence or experience in the field.

In light of the findings above, it may be argued that it would be better for those advertising their skills in implant dentistry to avoid the use of such potentially confusing titles altogether. Instead, they could more clearly align their advertisements to show adherence to the FGDP's Training Standards in Implant Dentistry ${ }^{18}$, and have developed their competence in the procedures involved in clinical assessment, treatment planning, and the placement and restoration of implants through a training course in implant dentistry with a suitably trained clinician as a mentor. Further information on the length of experience, the number of cases treated and the complexity of cases handled (straightforward or complex as defined by $\mathrm{FGDP}^{18}$ ) could then enable prospective patients to have much more objective information as to the experience and skills of practitioners offering these services.

Of further concern, $8 \%$ of the websites reviewed made claims that at least one practitioner had specialist status where, upon inspection of the GDC Registers, this was shown not to be the case at all. Similar results have been found in earlier surveys in $2005^{19}$ and $2011,{ }^{20}$ in which unfounded specialist status was being claimed in $2 \%$ and $6 \%$ of the websites reviewed, respectively. The higher levels of unfounded claims identified in this study may be due to these earlier audits including all dental practice websites, selected at random, rather than 
being restricted only to those delivering more advanced services as described in this study.

On a related point, the GDC 2012 guidance did clarify that listing memberships or fellowships of professional associations or societies can also mislead those carrying out the search. ${ }^{9}$ The letters may imply to the public that a registrant has attained a certain level of skill, which in fact may not be the case. The audit however revealed that such practices remain common and 52\% of practice websites reviewed still present such information, including membership and fellowship of a range of dental associations, academies, societies and foundations.

Sixty percent of practice websites titled the registrant as Doctor ('Dr') when there was no evidence that the practitioner had either an MBBS or PhD-level qualification. In 1999, while the GDC decided that it would no longer object if dentists chose to use ' $\mathrm{Dr}$ ' as a courtesy title, they did so with the provision that registrants made it clear that they were dentists by adding the terms dentist, dental surgeon or dental practitioner after their names so that patients were not misled. Notwithstanding this advice, in 2013 the ASA upheld a test case of the use of the title 'Dr' at Woodvale Dental Clinic, ${ }^{21}$ where the registrant clearly listed relevant dental qualifications and specialist status after their name. The ASA's final assessment however stated that the website in question did not explain that the title 'Dr' was a courtesy title only, and therefore concluded that the advertisement was likely to mislead. The claim was thus adjudged to breach CAP Code (edition 12), rules 3.1 (misleading advertising) and 3.7 (substantiation). Results presented herein clearly show that there is still a considerable lack of compliance with current GDC or ASA advice over these matters, suggesting that the potential to mislead the public remains a concern, and may well result in more action being taken by the ASA should the sector not act further to self-regulate.

In terms of web accessibility, it appears that dental practice websites have not yet generally recognised their obligations under the Equality Act. While there is no absolute standard as to what is considered 'accessible', the fact that none of the websites reviewed had any means to alter text size, only $20 \%$ met the WCAG 1.0 level-A standard and $8 \%$ the WCAG 2.0 level-A standard, clearly shows that many dental practice websites fall short of the current minimal web accessibility standards. The vast majority of websites that fell short of these standards did so due to the lack of text alternatives to non-text elements such as images. On a more positive note, $6 \%$ of the websites met the full WCAG 2.0 double-A standard, and a further 34\%

\begin{tabular}{|c|c|c|c|}
\hline \multirow{2}{*}{ GDC 2012 standard } & \multicolumn{3}{|c|}{ Websites adhering to standard (\%) } \\
\hline & $\begin{array}{l}\text { Addy et al. } \\
2005^{19}\end{array}$ & $\begin{array}{l}\text { Nichols \&t } \\
\text { Hassall } 2010^{20}\end{array}$ & $\begin{array}{l}\text { This study } \\
2014\end{array}$ \\
\hline $\begin{array}{l}\text { Website showing professional qualifications (and } \\
\text { country from which gained }\end{array}$ & $70(65)$ & $68(58)$ & $86(78)$ \\
\hline $\begin{array}{l}\text { Website showing registrants GDC registration } \\
\text { number. }\end{array}$ & 7 & 19 & 64 \\
\hline Website showing name (and geographic address) & $87(90)$ & $96(98)$ & 94 \\
\hline $\begin{array}{l}\text { Website showing practice contact details (email } \\
\text { address; telephone number) }\end{array}$ & $73 ; 90$ & $85 ; 100$ & 94 \\
\hline Website showing GDC's address or link & 17 & 19 & 38 \\
\hline Website showing practice complaints procedure & N/A & 9 & 26 \\
\hline Website showing date last updated. & 11 & 8 & 46 \\
\hline
\end{tabular}

would have met this standard if the issues preventing the lower level-A standard had been resolved. The majority of issues leading to failure to meet double-A standards were due to the use of colours and contrasting colours that would render the website inaccessible for partially sighted people.

Even for those without any disability, the general usability of websites was often poor, with only 6\% having any search facility built into the site. Clearly few dental practitioners actually produce their own website, but employ consultants or contractors to provide this service. It is perhaps surprising then that such poor adherence to standards is being achieved, and in future it may well be advisable if dental practitioners are more prescriptive in stipulating such standards within the contracts made with their website designers.

Finally, it is interesting to consider whether the recent GDC guidance has actually had an impact on web advertising standards since it was published in 2012. Unfortunately there is little baseline information with which to compare the results of this study. Two earlier surveys in $2005^{19}$ and $2011^{20}$ randomly selected dental practice websites rather than focusing on any offering more advanced procedures, such as implant placement as described herein. The website search methodologies used in these earlier studies were also quite different to that used in this study. However accepting these limitations, some tentative trends can be suggested (see Table 2).

There does appear to be a gradual improvement in compliance with many aspects of the GDC's standards over the years. Particularly noteworthy is the increase in the proportion of sites now displaying the GDC number of the registrant, with a considerable rise also in sites linking to the GDC website itself, and also in those showing when the website was last updated. While the number of sites displaying a complaints procedure is still low it is noticeably improved when compared with the 2010 study. Overall it appears that while compliance levels with some of the GDC criteria remain low, the sector is in fact moving forward to meet the standards laid down by the regulatory body. Whether the pace of improvement in compliance is seen as acceptable or not is something that policymakers may well have to consider in future years.

\section{CONCLUSION}

At a time when registrants have at their disposal a wide range of tools and guidance to allow them to develop a practice website that adheres to relevant GDC, ASA, and Equality Act guidelines, this study clearly shows that a significant number of implant practice websites are still falling short of minimal standards.

The use of the terms 'implantologist' and/ or 'implant specialist' on practice websites are widespread, but convey little meaning in terms of registered status, experience or proven clinical ability, and may therefore lead to confusion within the public. Further consideration by, and clarification from, the GDC may well therefore be beneficial.

Use of the term 'Dr' as a courtesy title remains open to some interpretation by the regulatory authorities. Recent rulings suggest that practitioners should make it very clear that the title is a courtesy title only.

At a time when implant treatment, communications (web) technology and professional and legal regulations are all changing rapidly, dental registrants are urged to regularly review their own practice websites and make necessary changes on an ongoing basis.

\footnotetext{
1. McCollough L V. Elements of an effective dental website. J Okla Dent Assoc 2011; 102: 24-25. 2. Michaels R L. Ten top tips: building a great dental
} 
website. Tex Dent J 2005; 122: 484-486.

3. Miller S A, Forrest J L. Dental practice websites: creating a web presence. Dent Clin North Am 2002; 46: 463-475.

4. Neely M H. Branding your practice: twelve practical steps to creating lifelong patient relationships. J Med Pract Manage 2005; 20: 266-270.

5. Ni Riordáin R, McCreary C. Dental patients' use of the internet. Br Dent J 2009; 207: 583-586.

6. Office for National Statistics. Statistical bulletin: internet access - households and individuals, 2012 part 2. 2013. Online information available at http:// www.ons.gov.uk/ons/rel/rdit2/internet-access--households-and-individuals/2012-part-2/stb-ia2012part2.html (accessed November 2014).

7. Advertising Standards Authority. The CAP code: the UK code of non-broadcast advertising, sales promotion and direct marketing. 12th ed. London: The Stationary Office, 2010.

8. General Dental Council. Standards for dental professionals. 2005. Online information available at http:/ www.gdc-uk.org/Dentalprofessionals/Standards/ Pages/default.aspx (accessed November 2014).

9. General Dental Council. Principles of ethical advertising. 2012. Online information available at http://
www.gdc-uk.org/Dentalprofessionals/Standards/ Pages/Ethical-advertising.aspx (accessed November 2014).

10. General Dental Council. New guidance on ethical advertising. GDC Gazette 2012; Spring: 6-7.

11. Torlot N. DDU welcomes GDC's guidance on ethical advertising. 2012. Online information available at http://www.theddu.com/guidanceandadvice/ latestupdatesand-advice/dduwelcomesgdcsguidanceonethicaladvertising (accessed November 2014).

12. Straumann's 2012 capital markets day in Amsterdam. How will dentistry look in 2020. 2012. Online information available at http://www.straumann.com/cmd (accessed November 2014).

13. Österle A, Balázs P, Delgado J. Travelling for teeth: Characteristics and perspectives of dental care tourism in Hungary. Br Dent J 2009; 206: 425-428.

14. General Dental Council. Implantology - policy statement. 2012. Online information available at http://www.gdc-uk.org/Dentalprofessionals/ Standards/Pages/Implantology.aspx (accessed November 2014)

15. BBC News. Dental implants can cause nerve damage, warns study. 2012. Online information available at http://www.bbc.co.uk/news/health-18366437 (accessed November 2014)

16. StatCounter GlobalStats. 2014. Online information available at http://gs.statcounter.com (accessed November 2014)

17. Chitikia Inc. The value of Google result positioning. 2013. Online information available at http://chitika. com/googlepositioningvalue (accessed November 2014).

18. Faculty of General Dental Practice. Training standards in implant dentistry. 2012. Online information available at http://www.fgdp.org.uk/_assets/pdf/ publications/policy\%20documents/implant $\% 20$ training\%20stds\%20jun\%2012.pdf (accessed November 2014).

19. Addy L D, Uberoi J, Dubal R K, McAndrew R. Does your practice website need updating? Br Dent J 2005; 198: 259-260.

20. Nichols L C, Hassall D. Quality and content of dental practice websites. Br Dent J 2011; 210: E11.

21. Advertising Standards Authority. ASA Adjudication on Woodvale Clinic. 2013. Online information available at http://www.asa.org.uk/Rulings/ Adjudications/2013/5/Woodvale-Clinic/ SHP_ADJ_206574.aspx\#.VAQD-Uslcds (accessed November 2014). 